\title{
La Hermenéutica analógica-icónica: una herramienta para la investigación en las artes visuales
}

Dr. Leonel De Gunther Delgado

Correo: Igunther@capomo.uson.mx

M.M. Fernando Serrano Arias

Correo:fserranoa@capomo.uson.mx

Universidad de Sonora

Departamento de Bellas Artes

Recibido para su publicación: 30 de agosto de 2015

Aprobado: 01 de octubre de 2015

\section{Introducción}

All the world's a stage, and all the men and women merely players. They have their exits and their entrances; And one man in his time plays many parts. (As You Like it, 1599).

William Shakespeare

La hermenéutica analógica-icónica como una disciplina orientada a la interpretación de "textos" ha cobrado interés en los últimos años. La creciente publicación de estudios que exploran su utilidad en diferentes áreas de conocimiento como la psicología, el psicoanálisis, la sociología, las artes, la literatura, la antropología, el derecho y la política constituyen muestras de ese interés cuyo propósito consiste en dar cuenta de la necesidad de una interpretación moderada, prudente, analógica. Una interpretación que no apele a un único sentido ("ideas claras y distintas" como lo habría dicho Descartes) ni otra que se dispare hacia la multiplicidad de los sentidos (la deriva posmoderna); sino una interpretación analógica, prudente, "sutil" (Beuchot, 2006), colocada entre las dimensiones del límite y lo ilimitado.

Siguiendo la lógica de la hermenéutica analógica-icónica, desde una perspectiva de exploración y diálogo con el arte, este trabajo tiene el propósito de reconocer los alcances y límites de la hermenéutica analógica-icónica aplicada a la interpretación de algunas escenas de "Chicago" (2002) de Marshall, una película que poetiza la vida prosaica y vuelve prosaica la vida poética; se trata de un ejercicio que contribuye con herramientas metódicas a un campo tan amplio y ambiguo como es el de las artes visuales.

Para ello, empleamos como útil conceptual la noción de "analogicidad", que resulta adecuada para interpretar las secuencias narrativas de "Chicago", donde el "texto", ins- crito en la imagen, dota de sentido de manera simétrica el salto entre la realidad y la fantasía, sin reducir la una a la otra.

El texto se divide en tres partes. La primera esboza la hermenéutica analógica-icónica y pone en juego aquellos útiles conceptuales que emplearemos para interpretar algunos fragmentos de la película, la segunda parte ofrece la estrategia metódica seguida para realizar este ejercicio teórico-práctico; mientras que la tercera, muestra, a través de un ejemplar, el estudio interpretativo, cerramos el texto con algunas consideraciones finales.

\section{Hermenéutica analógica-icónica}

La hermenéutica analógica-icónica de Beuchot se coloca en las numerosas tendencias actuales de la hermenéutica surgidas desde y tras Gadamer (Beuchot \& Arenas-Dolz, 2008; Grondin, 2006), aunque cabría agregar que éste no sólo recupera a los clásicos; sino también las posturas medievalistas y algunas de las posiciones actuales de la corrientes tanto continentales como analíticas.

Para Mauricio Beuchot, el interés de estudio de la "hermenéutica analógica-icónica" es la interpretación de textos o si se prefiere, la búsqueda de su "sentido auténtico". En esta primera definición se deja por sentado que el interés de la hermenéutica es la interpretación de textos, pero que significa aquí: ¿analógica?, ¿icónica?, ¿texto?, ¿sentido auténtico? Revisemos de manera general las nociones señaladas.

El término "ana-logía" - del griego- significa "según razón" o "proporción". También significa "pasar a un orden superior" (guarda un cierto aire de familia con la dialéctica), que es semejante al sentido de la palabra latina "pro-portio", la cual significa "proporcionalidad". Se entiende tam- 
bién como semejanza, pero sin ser reductible a ella; ya que implica el predominio de la diferencia. Se puede entender también como "reconocimiento de límites o la trasgresión ordenada no violenta de los mismos" (Beuchot \& Arenas-Dolz, 2008, p. 31); en una palabra: prudente; por lo que también es frontera y es a la vez puente: es una relación entre relaciones múltiples y heterogéneas más que entre cosas.

De los múltiples sentidos anteriores, podríamos señalar que la analogía constituye uno de los atributos centrales de la hermenéutica analógica-icónica, ya que con ella, podemos moderar la interpretación sin reducirla a una sola ni tampoco dejarnos llevar por cualquier interpretación posible: la noción de límite, puente y proporcionalidad son aquí figuras clave, ya que permiten moderar el traslado de un dominio de conocimiento a otro, colocarla entre el límite (univocismo) y lo ilimitado (equivocismo). En este sentido, la hermenéutica analógica-icónica se coloca así en una posición intermedia: ni aceptamos una sola interpretación ni tampoco la multiplicidad de las mismas; en cambio, permite identificar la existencia de varias interpretaciones, donde alguna de ellas es más adecuada que las otras: las nociones de "proporcionalidad" y "atribución" hacen aquí su aparición, con ello, reconocemos y conservamos la diferencia y construimos puentes de relación entre los fenómenos: lo que está al frente de los sentidos.

La noción de icónica, dentro del membrete, es introducida por Beuchot (2002), para poner en juego algunas ideas de Pierce, con ello, construye un puente entre analogía e "icono". Para Pierce ${ }^{1}$, el ícono abarca tres tipos de signo: imagen, diagrama y metáfora. La imagen es lo más cercano a la interpretación única -el llamado "univocismo"-, la metáfora se dispara hacia las múltiples interpretaciones -el llamado "equivocismo"-; mientras que el diagrama fluctúa entre ambos ${ }^{2}$. Para Beuchot, es la analogía lo que se acerca al ícono pirceano.

Las ideas anteriores, permiten encontrar una discursividad cercana a lo unívoco como en la imagen, una interpretación profunda a través de la semejanza de relaciones como en el diagrama y una interpretación equivocista a través de la metáfora. La analogía abarca entonces no sólo la imagen, el diagrama y la metáfora, sino también, algunos aspectos específicos como la atribución y la proporcionalidad, es decir, no sólo se trata de la tensión entre significado literal y metafórico ni sólo de la tensión dialéctica entre verdad literal o metafórica, sino del reconocimiento de la analogía en toda su extensión.

Beuchot agrega que la analogía nos obliga a atender a los elementos contextuales y particulares; mientras que el icono nos obliga a interpretar desde las hipótesis parciales y diagramáticas enunciadas siguiendo una trayectoria de la parte al todo. Esto con el propósito de alcanzar la compresión más completa que es asequible: una objetividad fragmentada, limitada, pero suficiente (Beuchot, 2002).

Por otro lado, el sentido de "texto" es amplio, hace referencia a textos escritos, orales o actuados, lo cual, como intérpretes, permite abordar una amplia variedad de textos susceptibles de interpretación, mientras que sentido auténtico se relaciona con la intención del autor. Ésta se representa a través de su contenido en diferentes niveles de análisis: gramatical, semántico y pragmático. Tales dimensiones permiten contextualizar al texto en la encrucijada donde se unen el respeto a la intención del autor y nuestra interpretación. Se trata de la dimensión dialéctica que emerge en el diálogo autor, texto e intérprete, sin perder por ello su proporcionalidad la cual tiene que ver con la moderación epistémica y práctica.

La manera o procedimientos que emplea la hermenéutica analógica-icónica para llevar a cabo la interpretación -su metodología-, no es "preceptiva", podría plantearse como exploración, diálogo y búsqueda de los significados textual, intra-textual, inter-textual e incluso transtextual a través del empleo de las "sutilezas" : para entender o para implicar. Para ello es necesario pre-suponer la estructura gramatical: orden y estructura, la dimensión semántica o relación entre el sentido y la referencia y la dimensión pragmática o intencionalidad. Lo anterior se esquematiza como sigue: (1) la búsqueda de un mundo para el texto, (2) la explicación-comprensión que da la búsqueda del mundo que puede corresponder al texto y (3) con la aplicación pragmática se busca esa objetividad del texto, que 
es la intención del autor. Se trata de un método "hipotético deductivo". En la interpretación se emiten hipótesis interpretativas frente al texto, para tratar de rescatar la sino del reconocimiento de la analogía en toda su extensión.

Beuchot agrega que la analogía nos obliga a atender a los elementos contextuales y particulares; mientras que el icono nos obliga a interpretar desde las hipótesis parciales y diagramáticas enunciadas siguiendo una trayectoria de la parte al todo. Esto con el propósito de alcanzar la compresión más completa que es asequible: una objetividad fragmentada, limitada, pero suficiente (Beuchot, 2002).

Por otro lado, el sentido de "texto" es amplio, hace referencia a textos escritos, orales o actuados, lo cual, como intérpretes, permite abordar una amplia variedad de textos susceptibles de interpretación ${ }^{3}$, mientras que sentido auténtico se relaciona con la intención del autor. Ésta se representa a través de su contenido en diferentes niveles de análisis: gramatical, semántico y pragmático. Tales dimensiones permiten contextualizar al texto en la encrucijada donde se unen el respeto a la intención del autor y nuestra interpretación. Se trata de la dimensión dialéctica que emerge en el diálogo autor, texto e intérprete, sin perder por ello su proporcionalidad la cual tiene que ver con la moderación epistémica y práctica.

La manera o procedimientos que emplea la hermenéutica analógica-icónica para llevar a cabo la interpretación -su metodología- , no es "preceptiva", podría plantearse como exploración, diálogo y búsqueda de los significados textual, intra-textual, inter-textual e incluso transtextual a través del empleo de las "sutilezas" ${ }^{4}$ : para entender o para implicar. Para ello es necesario pre-suponer la estructura gramatical: orden y estructura, la dimensión semántica o relación entre el sentido y la referencia y la dimensión pragmática o intencionalidad. Lo anterior se esquematiza como sigue: (1) la búsqueda de un mundo para el texto, (2) la explicación-comprensión que da la búsqueda del mundo que puede corresponder al texto y (3) con la aplicación pragmática se busca esa objetividad del texto, que es la intención del autor. Se trata de un método "hipoté- tico deductivo". En la interpretación se emiten hipótesis interpretativas frente al texto, para tratar de rescatar la intención del autor, y después se ven las consecuencias de la interpretación, sobre todo mediante el diálogo con los otros intérpretes (Beuchot, 2002).

En este sentido, la hermenéutica analógica-icónica es un mecanismo o herramienta útil para la interpretación de textos, prudente, ya que derivado de su elasticidad, es aplicable tanto a textos metafóricos y otros textos figurados, como textos no figurados o no trópicos, sino históricos, psicológicos o sociológicos $y$, asumimos aquí los cinematográficos, que por la atribución (orden) y la proporcionalidad no pierdan la riqueza de sus diferencias principales, pero también puedan manejarse discursivamente (Beuchot, 2002).

\section{Estrategia metódica}

Para la aplicación de esta orientación teórica, elegimos algunas de las escenas de la película "Chicago". Su elección obedece a que el discurso narrativo resulta susceptible, de un análisis e interpretación siguiendo algunas de las pautas que hemos presentado en la primera parte de este texto.

Su propósito específico consiste en re-conocer el alcance y limitación de la hermenéutica analógica-icónica, a través de la noción de "analogicidad", constituida por las analogías de atribución, proporción y metafóricas, en la interpretación de algunas de las escenas de la película "Chicago". La hipótesis de trabajo, de naturaleza interpretativa, que enunciamos con el propósito de seguir las condiciones lógicas de operación de esta hermenéutica se enuncia como sigue: la vida prosaica (cotidiana) re-presentada en la película Chicago, se transfigura en vida poética (creativa, imaginativa) a través de la analogía de proporcionalidad que, como bucle recursivo ${ }^{5}$, vuelve poético lo prosaico y prosaico lo poético de manera re-currente.

Esta hipótesis permite, primero, la exploración y diálogo con el fragmento, una conversación que va de la parte hacia el todo (los fragmentos representados a través de las escenas nos orientan hacia el todo), como un orientador inicial. Segundo, el con-texto y las particularidades del mis- 
mo. La contextualización como lo ha notado Motta, "produce cierta ignorancia necesaria sobre ciertas dimensiones de lo conocido, no por limitación de una capacidad, sino para dotar al sujeto de una optimización de la eficacia del funcionamiento cognitivo" (2006, p. 19). Es decir, la contextualización ofrece tanto las condiciones para insertar el conocimiento actualizable como los límites de validez a través de una visión que re-liga y articula la perspectiva selectiva (mirar el fragmento) y global (mirar el todo) de manera combinatoria (pensar globalmente, actuar localmente). De aquí se desprende la similitud que es posible encontrar entre contexto y analogía: la relación entre relaciones múltiples y heterogéneas.

A través de la hipótesis interpretativa señalada más arriba, podemos partir de una noción transitiva -hacer comprender- para la interpretación de los fragmentos y del contexto de la película. Esto también permite (1) la búsqueda de un mundo para el texto en sus dimensiones de intra, inter o transtextualidad (sentido y referencia), (2) la explicación-comprensión que da esta búsqueda y que puede corresponder al texto y (3) alcanzar esa "objetividad fragmentada", limitada, pero suficiente del texto que es la intención del autor.

La secuencia narrativa de la película "Chicago" presenta diferentes escenas para su análisis e interpretación. Trece de ellas poseen una estructura similar: (1) muestran "entradas formales", un tipo de operación selectiva que sin duda remite a un plano ideológico, (2) son anunciadas por un presentador, cuyas inflexiones de voz -entonación- resulta conveniente en el mundo del espectáculo (3) cada secuencia narrativa se desdobla en dos planos en los cuales ocurren historias paralelas: por un lado corre la vida común o prosaica y por el otro, la vida poética. Es un inter-juego que mezcla la realidad con la fantasía o viceversa. Cuatro secuencias narrativas más siguen el mismo patrón; pero omiten al presentador, también identificamos la recurrencia de ciertos signos que funcionan como metáforas, cuyo sentido sólo es asequible en el desdoblamiento de un contexto imaginario entre la realidad y la ficción.

\section{De la vida prosaica a la poética o de la vida poética a la prosaica (o viceversa)}

En las secciones anteriores enunciamos como hipótesis interpretativa que el filme transfigura la vida prosaica como vida poética y la vida poética como vida prosaica empleando un mecanismo analógico, en particular la denominada analogía de proporcionalidad. Toca ahora responder a las preguntas sobre el contexto y ofrecer algunos ejemplos de aplicación como de la interpretación y las consecuencias de la misma.

\section{"Chicago", el contexto}

La película "Chicago" fue estrenada en el año 2002, en los Estados Unidos bajo la dirección de Rob Marshall (usamos aquí la versión española de 2003), contando con los papeles estelares de Renée Zellweger, Catherine Zeta-Jones, y Richard Gere, además de Queen Latifah, John C. Reilly, Lucy Liu y Taye Digs entre otros. Reconoce además estar basada en el Musical "Chicago" dirigido y coreografiado por Bob Fosse y en la obra original de Maurine Dallas Watkins titulada bajo el mismo nombre.

Algunas de las frases que emergen en los diálogos de la película como: "Otra mujer bonita libre", "En esta ciudad -Chicago- el asesinato es un entretenimiento", “... y [para] una carita tan mona como la tuya, en Chicago, la justicia no está ciega", "Algún consejo para que las mujeres se aparten del jazz y la bebida". Lo mismo ocurre con el "cambio de imagen" de una de las asesinas -Roxie Hart- en la cual aparece la fotografía de Beulah Annan, la verdadera asesina, mientras ella se hace un corte de pelo y se pinta: la imagen de la sofisticación; así como también, la imagen trastocada de la ley: "Fame: their names and deeds", mientras entran a la sala de la corte ( $¿$ el discurso de Pericles para honrar a los muertos de la guerra del Peloponeso? E incluso las expresiones del abogado: "Todo es un circo, un circo de tres pistas, el mundo entero es un gran espectáculo... [Donde actuamos todos]. Estos aspectos sólo encajan en la variabilidad de un contexto específico, el de Chicago de los años veinte y en los artículos escritos por Maurine Watkins y en su obra de teatro, aunque también es cierto que los juicios 
de O. J. Simpson, Amy Fisher, Louise Woodward (la niñera) e incluso el "niño pozolero" podrían adecuarse a estas características.

En 1924, Maurine Watkins, reportera del periódico estadunidense "Chicago Tribune", escribe la historia de dos mujeres asesinas: Belva Gaertner (Velma Kelly, en la película, Catherine Zeta-Jones) y Beulah Annan (Roxie Hart, en la película, Renée Zellweger), acusadas de asesinar, la primera a su marido; la segunda, a su amante. También cubre la historia de Leopold y Loeb, dos jóvenes acusados de asesinar a un joven sólo para mostrar su superioridad. Son los años de la depresión, de la prohibición del alcohol -que lo convertía en más popular-, de una ciudad bulliciosa, atenta a lo extraño, lo extravagante, lo sofisticado ${ }^{6}$. Son los tiempos también donde la violencia era considera potestad de los varones, cuando una mujer asesinaba, o se encontraba trastornada por el alcohol o era seducida por sus "emociones femeninas", lo que las hacia no responsables de los crímenes, donde los periodistas son transeúntes habituales de las cárceles -el área femenina de la cárcel del condado de Cook-, por las comisarías de policía, por las escenas del crimen. Las mujeres son escasas en este medio -la ganadora del Pulitzer, Louis Wille, en 1950, señala el acoso sexual de que era objeto-.

Es un tiempo donde la imagen del "vocero oficial" aún no ha sido propuesta en las instituciones, es el origen creciente de los "mass media", el espectáculo de la prensa, también de los derechos femeninos como el sufragio, pero también de otros, que operan en la clandestinidad: los cabaret de la época no reciben mujeres públicamente; pero si lo hacen a escondidas. Aunque para Watkins, Beulah y Belva estuvieron usando su género y sus encantos femeninos para manipular al sistema de justicia -en sus narraciones se encuentran amplias descripciones sobre su vestimenta y arreglo personal, así como de sus reacciones durante el juicio- otras mujeres asesinas como Sabella Nittti y Kitty Malm no pudieron usar su belleza o sofisticación para evadir la justicia -el caso de la "húngara", que ejemplificamos más abajo- (Goupton, 2003; Perry, 2010a, 2010b; Watkins, 1924a, 1924b).

\section{Las entradas formales y el uso de las analogías}

Las entradas formales teatralizadas, dotadas de un sentido particular a través de la voz del presentador, remiten a un plano ideológico, uno obtiene, a partir de su enunciación, una orientación sobre el contenido, un sentido y una referencia. Algunas de las entradas son: (1) "Las hermanas Kelly", (2) "En su primer número, Roxie Hart quiere ofrecerles una canción de amor y desamor dedicada a su querido marido Amos", (3) "Y ahora señoras y señores, la guardiana de las llaves, la reina de chirona, la zarina del pabellón de la asesinas, la matrona Mama Morton", (4) "Y ahora, las seis complacientes asesinas de la prisión de Cook nos ofrecen su interpretación del tango del pabellón", (5) "Señoras y señores presentamos al pico de oro, al príncipe de los tribunales, al único, al incomparable Billy Flint", (6) "Y ahora Billy Flint en el "Rag time" de la prensa", como verán no mueve los labios, sólo un poco": es un titiritero, (7) "Señoras y señores la señorita Velma Kelly en un número de desesperación".

Esta estructura común a cada una de las secuencias narrativas permite reconocer una posible interpretación que ofrece el uso de la analogía de proporcionalidad. Chicago, la película, puede ser vista como el gran escenario de vida en el que todos actuamos, donde el "gesto" se expande y teatraliza la vida o exhibe la vida teatralizada, como lo expresa el epígrafe que acompaña este texto; pero añadimos, es la mujer, en este caso, quien juega las muchas partes, en su tiempo.

La analogía de proporcionalidad describe una especie de relación simétrica, el ejemplo: "la razón es a los hombres lo que las emociones a los animales" ofrece de manera simultánea la posesión de atributos específicos que desdobla dos dimensiones de manera paralela, uno atribuible a los seres humanos; otras a los animales, une los contrarios pero conserva la diferencia, tal noción expresa simultaneidad, corren de manera paralela dos sentidos, en el caso que nos ocupa, veamos un ejemplo de aplicación en una de las secuencias narrativas.

La escena comienza con una conversación entre Roxie y Velma. Se oyen gritos a lo lejos: “iNo, no, soy inocente!. 


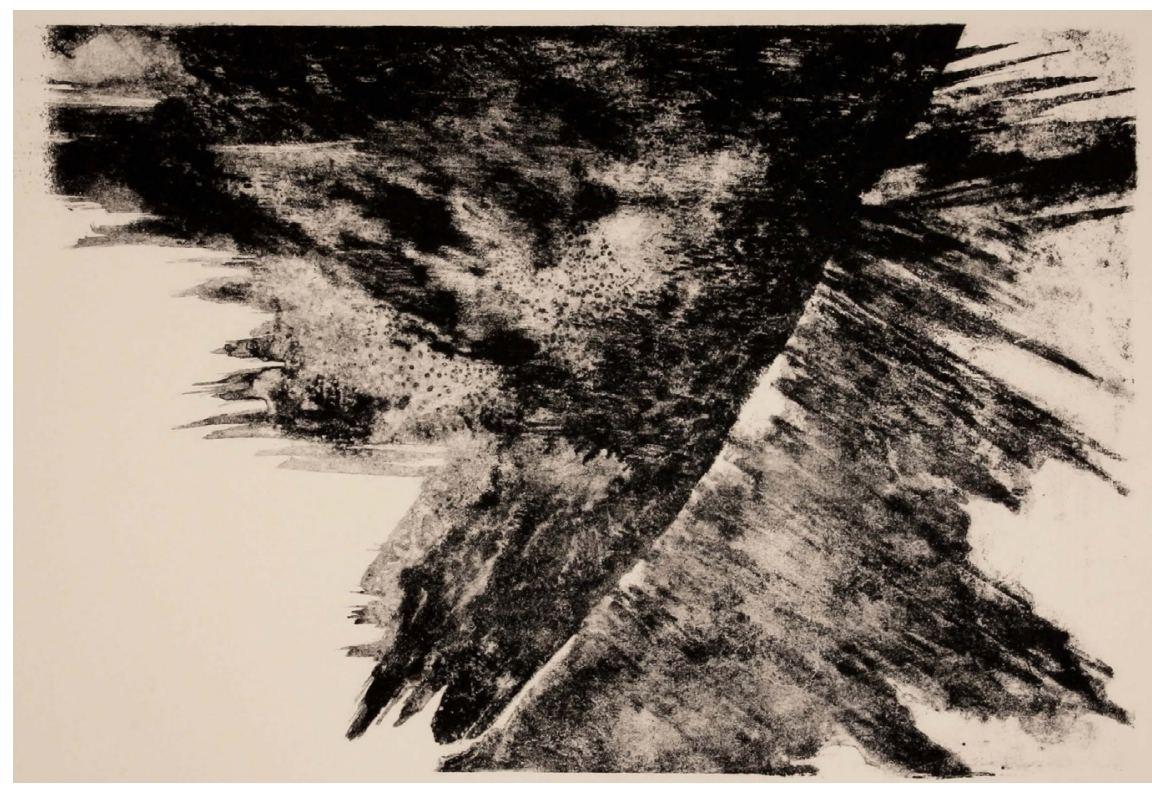

¿Qué sucede?, pregunta Roxie. Es la húngara. Ha perdido su último recurso. ¿Qué significa eso? Pues significa que... la semana que viene la van a... la frase no termina verbalmente, lo hace con un gesto donde Velma se coloca el índice frente a su cuello y lo mueve izquierda a derecha y cierra el puño. Después de decir esto se marcha... La escena muestra a una mujer mayor, con el uniforme de la prisión caminado por los pasillos en compañía de la matrona Mama Morton, no hay sofisticación en ella... Se escucha y ve la imagen de los narradores:

"Les habla Mary Sunshine desde la prisión del condado de Cook donde en el día de hoy se hará historia, Catlin Halensky se convertirá en la primer mujer ejecutada en el estado de Illinois"... Antes de terminar, entra la imagen de la Catlin orando frente a la imagen de una virgen... y por eso señoras y señores... Aquí se introduce a un nuevo presentador, es un varón..., cambia la imagen, ahora está en el camerino, maquillándose "Y a continuación, señoras y señores para su entretenimiento y disfrute, me enorgullece presentar a Catlin Halensky en su famoso número de desaparición húngara". Continúa el cambio de imágenes mientras el narrador habla. Tenemos al frente a una bella mujer iluminada a través de los reflectores, saluda a los espectadores que la observan, una escalera, es el componente visible del escenario. Ella comienza a subir, mientras los tambores hacen su redoble, de manera paralela, cuando las piernas de la bella mujer ocupan el primer plano, corre otra imagen, es Catlin subiendo las escaleras, al
Autor: Adriana Salazar Lamadrid

Título: Caos

Técnica: Litografía

Año: 2014

igual que en la escena anterior se observan sus piernas, su zapatos y su falda, el rostro entristecido, subiendo al patíbulo, volvemos a la imagen anterior, la bella mujer saluda al público, aparece otro componente del escenario, la soga, la secuencia narrativa muestra el rostro sombrío de Catlin, un celador le coloca la soga en el cuello, en la otra escena, la bella mujer se coloca la soga en la cintura y la ciñe, el policía ciñe la soga en el cuello de Catlin, el redoble de los tambores continúa, mientras que la bella mujer saluda por última vez a su público, camina sobre el trampolín hacia la orilla, Catlin camina hacia el piso falso que contiene el patíbulo, la bella mujer extiende su cuerpo, echa sus brazos hacia atrás, Catlin Ilora, algunos policías, Mama Morton y los asistentes a la ejecución miran la escena, los espectadores de la bella mujer están angustiados, Catlin está Ilorando, la bella mujer salta el vacío, el verdugo abre el piso falso, Catlin Ilora, los espectadores aplauden y gritan ibravo! a la bella mujer, solo queda una soga en movimiento, el cuerpo de Catlin cuelga... (Marcador 1:12:34-1:14:28; 1 minuto, 54 segundos).

En estos casi dos minutos de narración fílmica, la proporcionalidad entre el acto circense teatralizado y la ejecución "real" se liga sin sinterizar, de manera analógica uno con el otro. La simetría entre una vida poética y una vida prosaica se establecen de manera recursiva, la simetría entre los espacios, el escenario es un patíbulo, el escenario es una de las pistas de un circo, los espectadores concurren a una ejecución, el público concurre a un acto circense, las actrices (actores como categoría sociológica) ejecutan su número interpretando a su personaje: una llora, sufre, la otra saluda al público, una se maquilla, la otra reza, desea saltar al vacío, la otra espera que el mecanismo del patíbulo sea liberado. La muerte se poetiza, pero también se recrudece. El mecanismo de la analogía proporcional permite conectar dos ámbitos desconectados: un funeral no es una fiesta; ofrece un auxilio útil a las ideas claras y distintas, la llamada univocidad, mantiene a la vez, un orden de las interpretaciones posibles, la llamada analogía-, conservando la diferencia y múltiples interpretaciones que 
existen entre cada una de ellas -la llamada equivocidad-, pero manteniendo su unidad y diferencia (analogía), capta el contexto en movimiento, no reduce su variabilidad, en cambio ofrece pautas para ordenar la interpretación donde su adecuación constituye puntos de encuentro, no de síntesis superadora, sino de una objetividad débil, pero suficiente. Como experiencia estética llama al diálogo y a la conversación entre las dimensiones de lo humano, la racionalidad y la irracionalidad como partes constitutivas del arte visual. Con ello descubre, interpreta la intencionalidad del director, cercana tal vez, a la poetización de la vida prosaica como fenómeno recurrente y a la inversa. Las otras entradas que se han señalado más arriba, ofrecen pautas similares de interpretación, pero por motivos de espacio no las tocamos aquí.

Por último, hemos identificado la recurrencia de ciertos signos que funcionan como metáforas (en algunos casos impropias, su sentido solo es comprendido a través de la construcción de dos órdenes oracionales o de imágenes), cuyo sentido sólo es asequible en el desdoblamiento de un contexto imaginario entre la realidad y la ficción. Un ejemplo, al inicio de la entrada formal (4) "y ahora las complacientes asesinas... el tango del pabellón de la asesinas..." Una gota de agua que cae en el lavabo, los pasos de un vigilante, los dedos que tamborilean entre las rejas, los sonidos guturales y las expresiones constituyen el preludio que introduce la secuencia musical... cabría preguntarnos por el tango y sus sentidos y sobre su contexto también.

\section{A manera de conclusión}

En los apartados anteriores, describimos la llamada hermenéutica analógica-icónica de Mauricio Beuchot, cuyo de- sarrollo como disciplina filosófica con relativa autonomía ha alcanzado un amplio impulso. Nuestro propósito aquí, consistió en emplear algunos de sus recursos como útiles conceptuales para aplicarlos a la película Chicago con el fin de reconocer sus alcances y limitaciones de aplicación. Seguimos la lógica no preceptiva de aplicación metodológica: enunciación de hipótesis interpretativa para enfrentarnos al fragmento dentro de un contexto particular y global y enunciar nuestros propósitos. Pusimos especial atención en las analogías de proporcionalidad ya que como mecanismos de traducción son empleados con regularidad en las secuencias narrativas.

Dada la organización y estructura de las secuencias narrativas que se aprecian en esta película, es posible "leerla" en sus distintas dimensiones: superficial, a profundidad. Como resultado tenemos una objetividad débil, pero suficiente, de la intencionalidad del autor: la poetización de la vida prosaica y viceversa. La analogía de proporcionalidad que expusimos en nuestra hipótesis interpretativa funciona como un mecanismo central para transfigurar la vida prosaica en vida poética, la estructura narrativa, a través de entradas formales permite una orientación sobre el contenido y la analogía de proporción trasvasa los sentidos duales contenidos en la vida común a una poética, conservando sus diferencias a través de historias paralelas que concurren de manera simultánea: la vida real con la fantasía en la intertextualidad de la película y de su diálogo con el mundo en el que se inscribe.

Dejamos dos aspectos en la mesa de discusión (1) la revisión de la noción de contexto la cual resulta más compleja de lo que habitualmente reconocemos y (2) la Q12 relación entre analogía y contexto.

\footnotetext{
${ }^{1}$ Filósofo analítico estadounidense.

2 Pensemos como diagramas a los folletos que re-presentan las líneas de distribución del metro de la ciudad de México

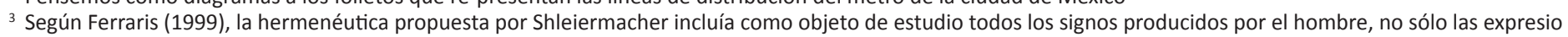
nes lingüísticas, sino también las naturales. El recorte y la apertura es posterior.

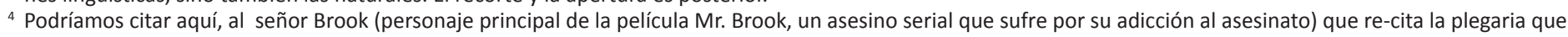

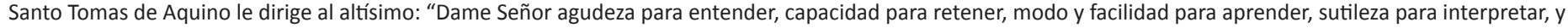
gracia abundante para hablar".

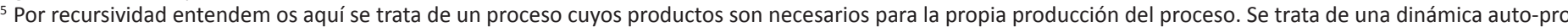
ductiva y auto-organizacional. Se trata de un bucle en el cual los efectos o productos son al mismo tiempo causante y productores del proceso mismo.

${ }^{6}$ Recordemos, aunque sea brevemente el sentido de sofista, en cuyo caso, es la raíz de sofisticado, sofisticación
} 


\section{Bibliografía}

Agamben, G. (2011). Desnudez (M. Ruvituso, M. D'Meza \& C. Sardoy, Trans. 1a ed. Vol. 427). Buenos Aires: Adriana Hidalgo editora.

Beuchot, M. (2002). Perfiles esenciales de la hermeneútica. México: Unam.

Beuchot, M. (2006). Puentes hermenéuticos hacia las humanidades y la cultura (1a ed.). México: Universidad Iberoamericana.

Beuchot, M., \& Arenas-Dolz, F. (Eds.). (2008). Hermenéutica de la encrucijada. Analogía, retórica y filosofía (1a ed. Vol. 25). Barcelona: Anthropos.

Ferraris, M. (1999). La hermenéutica (J. Bernal, Trans. 1a ed.). México: Taurus.

Goupton, N. (2003, 24 de marzo). Chicago: The True Murders That Inspired the Movie, National Geographic News. Retrieved from http://news.nationalgeographic.com/news/pf/97192069.html

Grondin, J. (2006). Introducción. In M. Beuchot \& F. Arenas-Dolz (Eds.), 10 palabras clave en Herméutica filosófica (pp. 27-52). Navarra: Verbo Divino.

Motta, R. D. (2006). La impertinencia del los conocimientos en la edad de hierro planetaria. In E. Morín \& R. D. Motta (Eds.), El desafió de la educación en el Siglo XXI: "Reaprender a Pensar". Ensayos introductorios al Pensamiento Complejo (1era ed.). México: SECNL-USAL-IIPC-ENS.

Perry, D. (2010a). The girls of the murder city. Fame, Lusut, and the beatiful killeres. Who inspired Chicago. New York: Penguin Group.

Perry, D. (2010b). Q\&A with Doug: Sex, murder and fame in Jazz Age Chicago. Retrieved noviembre 13, 2012, from http:// www.douglasperry.net/qa.html

Watkins, M. (1924a, 05 de abril). Demand Noose for 'Prettiest' Woman Slayer. Mrs. Annan Held on Murder Charge, Chicago Tribune, pp. 1-6.

Watkins, M. (1924b, 25 de mayo). Jury finds Buelah Annan is "Not Guilty", Chicago Tribune, pp. 1-5.

Título: Calidez

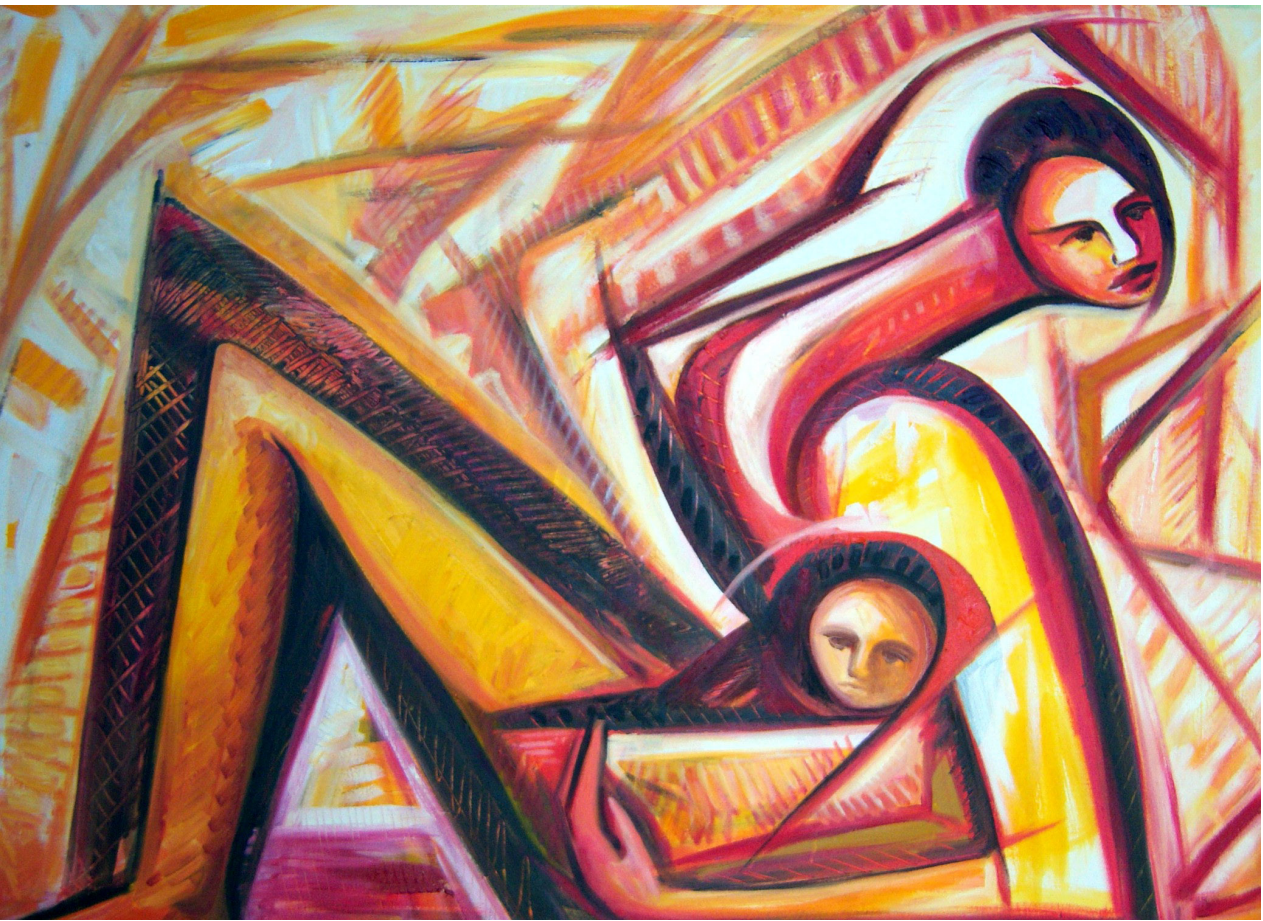

